\title{
Age-standardized expected years of life lost: quantification of cancer severity
}

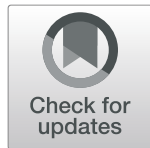

Yueh Wang ${ }^{1,2}$, Chun-Ju Chiang ${ }^{1,2}$ and Wen-Chung Lee ${ }^{1,2,3^{*}}$ (i)

\begin{abstract}
Background: The critical implications of the expected years of life lost (EYLL) index of cancer for health policy assessments have been largely overlooked. We advocate to standardize life lost indices.

Methods: Using the Taiwan Cancer Registry database as an example, we calculated the EYLL and the agestandardized EYLL to facilitate comparisons among cancer types (a total of 903,935 patients from the database). The International Cancer Survival Standard was used for calculating age-standardized EYLL.

Results: Pancreatic cancer is the most severe cancer in Taiwan, with the greatest age-standardized EYLL for the men (15.6 years) and women (18.0 years) as well as for the men and women combined (16.6 years). Negative correlations were observed between unstandardized EYLL of cancer and mean age at diagnosis.

Conclusions: The unstandardized EYLL represents an overall assessment of disease burden, whereas the agestandardized EYLL is a suitable measure of disease severity. We suggest that both measures be incorporated into routine annual reports of cancer statistics alongside the usual incidence and mortality rates and their agestandardized counterparts.
\end{abstract}

Keywords: Expected years of life lost, Age-standardization, Cancer, Burden of disease

\section{Background}

Cancer is a major public health problem worldwide; 17.5 million incident cases and 8.7 million mortality cases were reported for 2015 [1-7]. Cancer incidence and mortality rates and their age-standardized counterparts are used as references in cancer surveillance and cancer control in many countries [2, 8-13].

Expected years of life lost (EYLL) [14] is an alternative measure of the disease burden and economic effect. The EYLL of a patient with cancer can be interpreted as the patient's average deprivation of life due to cancer or the average life years that could be saved if the patient had not developed cancer $[1,15]$. Economic effect such as lifetime cost can also be derived via the EYLL and reimbursement database (for example, National Health Insurance Research Database in Taiwan) [15]. Therefore the EYLL is a useful index that reflects different aspects of health outcome. Recently, several studies have evaluated

\footnotetext{
* Correspondence: wenchung@ntu.edu.tw

${ }^{1}$ Taiwan Cancer Registry, Rm 506, No. 17, Xuzhou Rd., Taipei 100, Taiwan ${ }^{2}$ Institute of Epidemiology and Preventive Medicine, College of Public Health, National Taiwan University, Taipei, Taiwan

Full list of author information is available at the end of the article
}

disease burdens from the EYLL perspective [15-22]. However, compared with the widely used and wellrecognized indices of incidence and mortality rates, the critical nature of the EYLL index for health policy assessments has been largely overlooked.

In this paper, we advocate to standardize life lost indices. In the study reported herein, the age-standardized EYLL facilitated the comparisons of disease severity between cancer types and populations. Data regarding 20 major cancers from the Taiwan Cancer Registry were used in an example analysis.

\section{Methods}

We chose 20 cancer types listed as follows (in alphabetical order): bladder, brain, bronchus and lung, cervix uteri, colon, corpus uteri, esophagus, female breast, kidney, leukemia, liver, nasopharynx, non-Hodgkin lymphoma, oral cavity, ovary, pancreas, prostate, rectum, stomach, and thyroid (corresponding International Classification of Diseases for Oncology, Third Edition (ICD-O-3) codes and morphology codes are presented in Additional file 1: Table S1). In total, 903,935 patients 
were identified from the National Cancer Registry Database of the Taiwan Cancer Registry. The patients were aged more than 15 years and had received their diagnoses between 2006 and 2015. The patients were followed up until their deaths or until December 31, 2016, whichever came first.

Hwang and Wang's method was used to calculate the EYLL [14]. Specifically, the following four steps were performed.

1. For every patient under each type of cancer, we used the Monte Carlo method and the life table of the general population in Taiwan to randomly generate a survival time based on the patient's age, sex, and the year of diagnosis. For some rare cancers, we randomly generated more than one survival time for a patient, such that the total number of generated survival times was not less than 100,000. We then used the Kaplan-Meier method to obtain the survival curve for the generated reference population. The starting time of this survival curve was the time that the corresponding patient received the cancer diagnosis.

2. We calculated the survival curve of the patient population by using the same Kaplan-Meier method. The starting time of the survival curve was also the time at which the cancer was diagnosed.

3. For each time point $t$, the survival ratio between the patient population and reference population, $W(t)$, was assumed to be between 0 and 1 . We fit a restricted cubic spline model to logit $[W(t)]$ and then extrapolated the function to $t=80$. The function was subsequently back transformed into the original $W(t)$ function. Multiplying the survival function of the reference population from step 1 by the extrapolated $W(t)$, we obtained the extrapolated survival of the patient population.

4. The EYLL was calculated as the difference between the area under the survival curve of the reference population from step 1 and that under the survival curve of the patient population from step 2 (actual follow-up) and step 3 (extrapolation).

The bootstrap method was used to obtain the standard error of the EYLL with a resampling of 100 times. We used iSQoL2 statistical package R (http://sites.stat.sinica. edu.tw/isqol/) for the aforementioned computations.

The International Cancer Survival Standard (ICSS) [23] was used for age standardization of the EYLL. ICSS was formulated using the population-based cancer registry data from the European Cancer Registry Based Study on Survival and Care of Cancer Patients (EUROCARE) project (the project is now based on 22 countries in
Europe [24]). The Surveillance, Epidemiology, and End Results Program of the United States has also suggested using the ICSS as the standard for cancer survival analysis.

\section{Results}

As indicated in Table 1, the unstandardized EYLLs for the following three cancer types were greater than 15 years for the men and women combined: brain (22.5 years), esophagus (19.0 years), and pancreas (15.2 years). The data in Table 2 indicate that for the men, the unstandardized EYLLs for the following four cancer types were greater than 15 years: brain (20.0 years), esophagus (19.3 years), pancreas (15.2 years), and liver (15.2 years). Additionally, as indicated in Table 3, the unstandardized EYLLs for the following three cancer types were greater than 15 years for the women: brain (26.0 years), pancreas (15.8 years), and esophagus (15.0 years).

As shown in Table 1, the age-standardized EYLLs for the pancreas (16.6 years) and brain (15.7 years) were greater than 15 years for the men and women combined. Additionally, the EYLL associated with cancer of the pancreas (15.6 years) was greater than 15 years for the men (Table 2). As denoted in Table 3, four cancer types with age-standardized EYLLs greater than 15 years were observed for the women: pancreas (18.0 years), brain (17.1 years), liver (15.1 years), and esophagus (15.0 years). The unstandardized and the age-standardized EYLLs for all cancers were also presented in Table 1 (male and female combined), Table 2 (male), and Table 3 (female), respectively. Note that these include other minor cancer types that were not shown in this study.

Notable differences were identified between the unstandardized and age-standardized EYLLs for several cancer types. As indicated in Tables 1 and 2, the unstandardized EYLLs for cancer of the oral cavity in the men (14.6 years) as well as in the men and women combined (14.0 years) were greater than those for cancer of the bronchus and lung (12.2 years and 13.0 years, respectively). However, the converse was true after age standardization. The age-standardized EYLLs for cancer of the oral cavity in the men (10.0 years) as well as in the men and women combined ( 9.8 years) were smaller than those associated with cancer of the bronchus and lung (13.8 years and 14.0 years, respectively). In addition, the unstandardized EYLLs for cancer of the stomach in the men (9.2 years), women (10.1 years), and men and women combined (9.6 years) ranked in the middle among the 20 cancer types (the ninth, tenth, and tenth places, respectively), whereas the rankings of the corresponding age-standardized EYLLs (10.5, 10.8, and 10.6 years, respectively) were sixth, seventh, and seventh, respectively (Tables 1, 2 and 3). The rankings of the unstandardized EYLLs for cancer of the bronchus and lung 
Table 1 Unstandardized EYLLs and age-standardized EYLLs of 20 cancers in men and women combined in Taiwan (standard error in parenthesis)

\begin{tabular}{|c|c|c|c|c|c|c|}
\hline \multirow[t]{2}{*}{ Cancer type } & \multirow{2}{*}{$\begin{array}{l}\text { Number of } \\
\text { patients }\end{array}$} & \multirow{2}{*}{$\begin{array}{l}\text { Mean age } \\
\text { at diagnosis }\end{array}$} & \multicolumn{2}{|c|}{ Unstandardized } & \multicolumn{2}{|c|}{ Age-standardized } \\
\hline & & & EYLL (SE) & $\overline{\text { Rank }}$ & EYLL (SE) & Rank \\
\hline Pancreas & 17,994 & 67.6 & $15.2(0.2)$ & 3 & $16.6(0.2)$ & 1 \\
\hline Brain & 6929 & 49.4 & $22.5(1.5)$ & 1 & $15.7(0.3)$ & 2 \\
\hline Esophagus & 22,244 & 58.9 & $19.0(0.4)$ & 2 & $14.6(0.1)$ & 3 \\
\hline Bronchus and lung & 109,075 & 68.0 & $13.0(0.2)$ & 7 & $14.0(0.1)$ & 4 \\
\hline Liver & 112,904 & 64.5 & $14.7(0.1)$ & 4 & $14.0(0.1)$ & 5 \\
\hline Leukemia & 18,120 & 57.4 & $11.9(0.7)$ & 8 & $11.0(0.3)$ & 6 \\
\hline Stomach & 37,994 & 68.2 & $9.6(0.3)$ & 10 & $10.6(0.2)$ & 7 \\
\hline Ovary & 12,308 & 52.0 & $13.7(1.3)$ & 6 & $10.5(0.5)$ & 8 \\
\hline Oral cavity & 62,406 & 55.0 & $14.0(0.3)$ & 5 & $9.8(0.2)$ & 9 \\
\hline Nasopharynx & 15,699 & 51.0 & $10.5(0.9)$ & 9 & $8.0(0.3)$ & 10 \\
\hline Non-Hodgkin & 17,615 & 61.9 & $8.7(0.7)$ & 11 & $7.7(0.3)$ & 11 \\
\hline Kidney & 10,812 & 61.2 & $6.9(0.8)$ & 12 & $7.1(0.6)$ & 12 \\
\hline Colon & 79,349 & 66.6 & $6.3(0.2)$ & 14 & $6.5(0.1)$ & 13 \\
\hline Rectum & 53,339 & 64.7 & $6.7(0.3)$ & 13 & $6.3(0.2)$ & 14 \\
\hline Bladder & 20,920 & 69.6 & $5.3(0.3)$ & 18 & $5.6(0.3)$ & 15 \\
\hline Cervix uteri & 16,665 & 57.4 & $5.9(0.3)$ & 16 & $5.5(0.2)$ & 16 \\
\hline Corpus uteri & 17,336 & 54.3 & $5.4(0.9)$ & 17 & $5.1(0.4)$ & 17 \\
\hline Female breast & 96,204 & 53.9 & $6.0(0.5)$ & 15 & $4.3(0.2)$ & 18 \\
\hline Prostate & 43,320 & 73.2 & $2.8(0.2)$ & 19 & $3.4(0.5)$ & 19 \\
\hline Thyroid & 26,081 & 48.4 & $2.1(1.5)$ & 20 & $3.0(0.8)$ & 20 \\
\hline All cancers irrespective of types & 903,935 & 62.3 & $9.8(0.1)$ & - & $8.9(0.1)$ & - \\
\hline
\end{tabular}

Table 2 Unstandardized EYLLs and age-standardized EYLLs of 16 cancers in men in Taiwan (standard error in parenthesis)

\begin{tabular}{|c|c|c|c|c|c|c|}
\hline \multirow[t]{2}{*}{ Cancer type } & \multirow{2}{*}{$\begin{array}{l}\text { Number of } \\
\text { patients }\end{array}$} & \multirow{2}{*}{$\begin{array}{l}\text { Mean age } \\
\text { at diagnosis }\end{array}$} & \multicolumn{2}{|c|}{ Unstandardized } & \multicolumn{2}{|c|}{ Age-standardized } \\
\hline & & & EYLL (SE) & Rank & EYLL (SE) & Rank \\
\hline Pancreas & 10,224 & 66.7 & $15.2(0.2)$ & 3 & $15.6(0.2)$ & 1 \\
\hline Esophagus & 20,745 & 58.4 & $19.3(0.3)$ & 2 & $14.6(0.1)$ & 2 \\
\hline Brain & 3923 & 49.5 & $20.0(1.8)$ & 1 & $14.5(0.3)$ & 3 \\
\hline Bronchus and lung & 67,687 & 69.0 & $12.2(0.2)$ & 6 & $13.8(0.1)$ & 4 \\
\hline Liver & 78,676 & 62.6 & $15.2(0.1)$ & 4 & $13.4(0.1)$ & 5 \\
\hline Stomach & 23,977 & 69.0 & $9.2(0.3)$ & 9 & $10.5(0.3)$ & 6 \\
\hline Leukemia & 10,695 & 58.3 & $11.1(0.8)$ & 7 & $10.1(0.4)$ & 7 \\
\hline Oral cavity & 56,946 & 54.5 & $14.6(0.3)$ & 5 & $10.0(0.2)$ & 8 \\
\hline Nasopharynx & 11,882 & 51.1 & $10.2(0.8)$ & 8 & $8.0(0.4)$ & 9 \\
\hline Non-Hodgkin & 9669 & 62.3 & $8.6(0.9)$ & 10 & $7.5(0.4)$ & 10 \\
\hline Rectum & 32,286 & 64.8 & $6.6(0.3)$ & 11 & $6.1(0.2)$ & 11 \\
\hline Kidney & 7136 & 60.8 & $5.7(0.7)$ & 13 & $6.1(0.6)$ & 12 \\
\hline Colon & 43,822 & 66.8 & $6.1(0.3)$ & 12 & $6.0(0.2)$ & 13 \\
\hline Bladder & 14,869 & 69.5 & $4.3(0.4)$ & 14 & $4.6(0.3)$ & 14 \\
\hline Thyroid & 6188 & 49.9 & $4.1(2.7)$ & 15 & $4.1(0.8)$ & 15 \\
\hline Prostate & 43,320 & 73.2 & $2.8(0.2)$ & 16 & $3.4(0.5)$ & 16 \\
\hline All cancers irrespective of types & 502,842 & 63.7 & $10.6(0.1)$ & - & $9.7(0.1)$ & - \\
\hline
\end{tabular}


Table 3 Unstandardized EYLLs and age-standardized EYLLs of 19 cancers in women in Taiwan (standard error in parenthesis)

\begin{tabular}{|c|c|c|c|c|c|c|}
\hline \multirow[t]{2}{*}{ Cancer type } & \multirow{2}{*}{$\begin{array}{l}\text { Number of } \\
\text { patients }\end{array}$} & \multirow{2}{*}{$\begin{array}{l}\text { Mean age } \\
\text { at diagnosis }\end{array}$} & \multicolumn{2}{|c|}{ Unstandardized } & \multicolumn{2}{|c|}{ Age-standardized } \\
\hline & & & EYLL (SE) & Rank & EYLL (SE) & Rank \\
\hline Pancreas & 7770 & 68.7 & $15.8(0.4)$ & 2 & $18.0(0.4)$ & 1 \\
\hline Brain & 3006 & 49.1 & $26.0(2.1)$ & 1 & $17.1(0.5)$ & 2 \\
\hline Liver & 34,228 & 68.8 & $13.5(0.2)$ & 6 & $15.1(0.3)$ & 3 \\
\hline Esophagus & 1499 & 66.0 & $15.0(1.0)$ & 3 & $15.0(0.4)$ & 4 \\
\hline Bronchus and lung & 41,388 & 66.2 & $14.3(0.3)$ & 4 & $14.3(0.2)$ & 5 \\
\hline Leukemia & 7425 & 56.1 & $13.5(1.3)$ & 7 & $12.0(0.5)$ & 6 \\
\hline Stomach & 14,017 & 66.8 & $10.1(0.4)$ & 10 & $10.8(0.3)$ & 7 \\
\hline Ovary & 12,308 & 52.0 & $13.7(1.3)$ & 5 & $10.5(0.5)$ & 8 \\
\hline Kidney & 3676 & 61.8 & $10.6(1.6)$ & 9 & $9.2(1.0)$ & 9 \\
\hline Nasopharynx & 3817 & 50.7 & $11.5(2.5)$ & 8 & $8.6(0.8)$ & 10 \\
\hline Bladder & 6051 & 70.0 & $7.7(0.6)$ & 13 & $8.5(0.6)$ & 11 \\
\hline Non-Hodgkin & 7946 & 61.5 & $8.6(0.9)$ & 12 & $7.8(0.6)$ & 12 \\
\hline Oral cavity & 5460 & 60.4 & $9.2(1.2)$ & 11 & $7.7(0.5)$ & 13 \\
\hline Colon & 35,527 & 66.4 & $6.2(0.3)$ & 15 & $7.0(0.2)$ & 14 \\
\hline Rectum & 21,053 & 64.6 & $7.0(0.4)$ & 14 & $6.9(0.4)$ & 15 \\
\hline Cervix uteri & 16,665 & 57.4 & $5.9(0.3)$ & 17 & $5.5(0.2)$ & 16 \\
\hline Corpus uteri & 17,336 & 54.3 & $5.4(0.9)$ & 18 & $5.1(0.4)$ & 17 \\
\hline Female breast & 96,204 & 53.9 & $6.0(0.5)$ & 16 & $4.3(0.2)$ & 18 \\
\hline Thyroid & 19,893 & 47.9 & $1.5(2.1)$ & 19 & $3.6(1.1)$ & 19 \\
\hline All cancers irrespective of types & 401,093 & 60.4 & $8.6(0.1)$ & - & $8.0(0.1)$ & - \\
\hline
\end{tabular}

in the men (12.2 years) and in the men and women combined (13.0 years) were sixth and seventh, respectively, whereas the rankings of the corresponding age-standardized EYLLs (13.8 and 14.0 years, respectively) were both fourth. The ranking of the unstandardized EYLL for cancer of the liver in the women (13.5 years) was sixth, but the ranking of its agestandardized EYLL (15.1 years) was third.

Negative correlations of moderate magnitudes were observed between the unstandardized EYLLs and the mean corresponding patient ages at the time of diagnosis among 20 cancers in the men and women combined (Fig. 1a, correlation coefficient $=-0.20$ ), among 16 cancers in men (Fig. 1b, correlation coefficient $=-0.39$ ), and among 19 cancers in women (Fig. 1c, correlation coefficient $=-0.02$ ). These results indicated that a larger unstandardized EYLL for a cancer type may have been due to a younger mean age at diagnosis rather than greater severity. After age standardization, the negative correlations disappeared (Fig. 1d, correlation coefficient $=0.06$; Fig. 1f, correlation coefficient $=0.34$ ) or diminished in magnitude (Fig. 1e, correlation coefficient $=-0.13$ ). After adjusting the confounding effect of age, the age-standardized EYLL properly reflected the severity of the corresponding cancer type.

\section{Discussion}

Unstandardized EYLLs [16, 21, 22] were confounded by age at diagnosis and cancer severity. A patient with a cancer associated with relatively favorable prognosis may have a higher EYLL if the patient is of a relatively young age at the time of diagnosis. For example, cancer of the oral cavity (a cancer with a relatively favorable prognosis) in the men and women combined has the younger mean age at diagnosis of 55.0 years and greater unstandardized EYLL of 14.0 years than the corresponding figures for cancer of the bronchus and lung (a cancer associated with bleak prognosis) in the men and women combined (mean age at diagnosis: 68.0; unstandardized EYLL: 13.0 years). Therefore, the unstandardized EYLL may be used to represent overall disease burden, but it is not a suitable measure of disease severity.

The literature lacks studies that have applied age standardization in calculations of EYLL. This study fills that gap. Age-standardized EYLL may be used to facilitate the comparisons of the severities of cancer types. For example, pancreatic cancer corresponded with the greatest age-standardized EYLL in the men and women combined in Taiwan, indicating that patients with pancreatic cancer are likely to undergo a greater deprivation of life than did patients who receive diagnoses of other cancer types at the same age as the patients with 


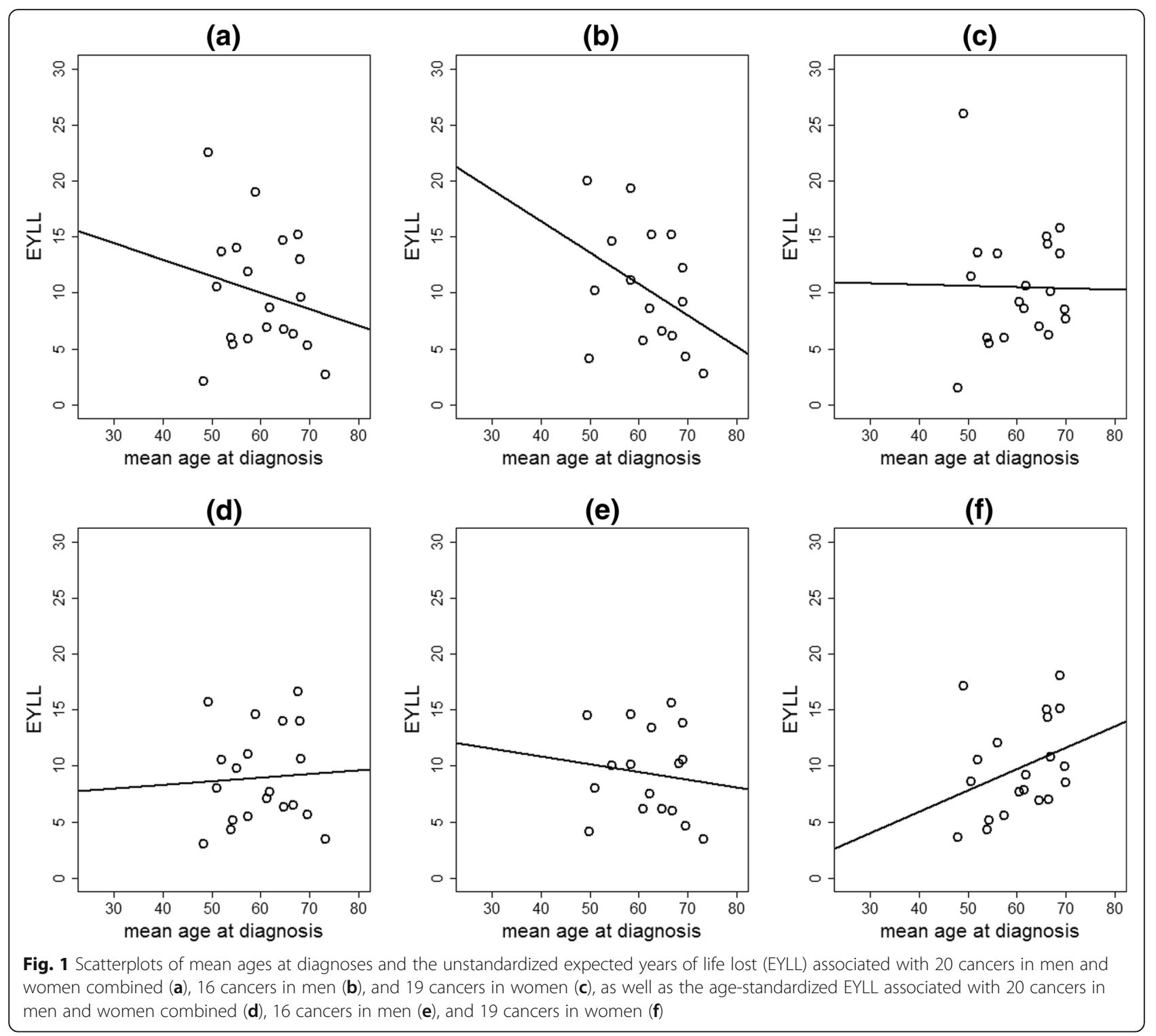

pancreatic cancer receive their diagnoses. Age standardization also enables comparison of the severity of a cancer type among countries. The World Health Organization (WHO) World Standard Population [25] is widely used in age standardization of indices based on general populations, such as indices for incidence and mortality rates [26]. By contrast, ICSS population is used in age standardization for indices based on patient populations, such as indices for survival proportion [27]. In this study, the EYLL was calculated based on patient population; therefore, ICSS was suitable for population age standardization. ICSS populations differ among cancer types: ICSS1 corresponds with cancers that increase in incidence as population age increases; ICSS2 corresponds with cancers that are broadly constant in incidence in relation to population age; and ICSS3 corresponds with cancers that mainly affect young adults [23]. To compare the severity of a specific cancer among countries or regions, the corresponding ICSS standard population for age standardization should be used. However, according to the concept behind the "identical weighting system" $[28,29]$, use of equal standard populations in comparisons of cancer types in a country or region is crucial for eliminating the confounding effect of age. Therefore, in this study, we used ICSS1 for severity comparisons among all cancer types.

From the individual perspective, it is appropriate to apply the age-specific EYLL to make inference about the life lost. We also calculated the age-specific EYLLs (5 strata: $15-44,45-54,55-64,65-74$, and > 75 years) associated with 20 cancers for the men and women combined, 16 cancers for the men, and 19 cancers for the 
women (Additional file 1: Tables S2-S4). Based on these results, a cancer patient in Taiwan can then be informed of his or her EYLL in accordance with age at the time of diagnosis and the type of cancer diagnosed. For example, a 60-year-old man diagnosed with oral cancer will have an EYLL of 11.9 years (Additional file 1: Table S3), and a 50-year-old woman diagnosed with cervical cancer will have an EYLL of 7.7 years (Additional file 1: Table S4).

Another well-known measure to evaluate cancer severities is the relative survival [30], which is the survival under a hypothetical situation that the disease of interest is the only cause of death. A relative survival is predicated on a given cut point of time, for example, the 3 -year or 5-year relative survival; information beyond that time point is totally discarded. By comparison, the EYLL is a complete follow-up of the expected life-time loss, not just limited to a cut-off time point. Moreover, the concept behind the EYLL may be helpful in better communicating cancer severity to the general public.

In addition to age standardization achieved using standard populations (such as the WHO standard population or the ICSS population), the lifetime cumulative sum of age-specific rates (or the weighted sum where life-table survival function or potential life lost is used as the weight) by itself may be used as an age-standardized index. For example, the cumulative rate of potential life lost and the lifetime years of potential life lost, previously proposed by Lee [31, 32], are age-standardized indices and can be interpreted as the expected years of potential life lost due to a specific cause of death during the lifetime of an individual. Such lifetime age standardization represents an alternative perspective from which to address the present EYLL problem and should be further studied. In this study, EYLL was determined using an incidence-based approach whereby patients with cancer were followed up for a period of time to monitor their survival statuses and the results regarding their lifespans were then extrapolated. By comparison, the years of potential life lost (YPLL) due to cancer is calculated using only the information of those who have died from cancer [21]. An additional advantage of the incidence-based approach is that it does not include cause-of-death information; therefore, it is immune to coding errors associated with calculations based on underlying causes of death. Finally, in this study, we used a restricted cubic spline model [14] for lifespan extrapolation. The "cure models" [33-35], which assume that excess hazard due to cancer decreases toward zero over time, are alternative (and potentially superior) methods for extrapolation.

\section{Conclusion}

The EYLL and age-standardized EYLL reveal disease burden and disease severity, respectively, which are critical measures from population-wide as well as individual perspectives. We suggest that both measures be incorporated into routine annual reports of cancer statistics alongside the usual measures of incidence and mortality rates and their age-standardized counterparts.

\section{Additional file}

Additional file 1: Table S1. ICD-O-3 code and morphological code used in this study. Table S2. Age-specific EYLLs for 20 major cancers in men and women combined in Taiwan. Table S3. Age-specific EYLLs for 16 major cancers in men in Taiwan. Table S4. Description of data: Agespecific EYLLs for 19 major cancers in women in Taiwan. (DOCX 34 kb)

\section{Abbreviation}

EYLL: Expected years of life lost

Acknowledgements

Not applicable.

Funding

This paper is supported by grants from the Health Promotion Administration, the Ministry of Health and Welfare in Taiwan (A1061011; the tobacco control and health care funds), the Ministry of Science and Technology in Taiwan (MOST 105-2314-B-002-049-MY3, MOST 104-2314-B-002-118-MY3 and MOST 107-3017-F-002-003), and the Public Health Research Center from the Featured Areas Research Center Program within the framework of the Higher Education Sprout Project by the Ministry of Education (MOE) in Taiwan (NTU107 L9003). No additional external funding was received for this study. The funders had no role in the study design, data collection and analysis, decision to publish, or preparation of the manuscript.

\section{Availability of data and materials}

The Taiwan Cancer Registry database is only available if any research institute has obtained permissions from the Department of Statistics, Ministry of Health and Welfare in Taiwan. For the cancer specific indices of the Taiwan Cancer Registry database, please refer to the link: https://cris.hpa.gov. tw/ (traditional Chinese only). For the application of the Taiwan Cancer Registry database usage, please contact the corresponding author (e-mail: wenchung@ntu.edu.tw) of this paper for more information.

\section{Authors' contributions}

W-CL conceptualized the hypothesis for this paper. YW and C-JC conducted the analysis, and all authors interpreted the results. YW prepared the first draft of the manuscript. All authors read, contributed to, and approved the final version of the manuscript. All authors have read and approved the manuscript, and ensure that this is the case.

\section{Ethics approval and consent to participate}

The study was approved by the IRB of the National Taiwan University Hospital (IRB no. 201801116RINA). Formal informed consent was not required due to the retrospective nature of the study.

\section{Consent for publication}

Not applicable.

\section{Competing interests}

The authors declare that they have no competing interests.

\section{Publisher's Note}

Springer Nature remains neutral with regard to jurisdictional claims in published maps and institutional affiliations.

\section{Author details}

${ }^{1}$ Taiwan Cancer Registry, Rm 506, No. 17, Xuzhou Rd., Taipei 100, Taiwan.

${ }^{2}$ Institute of Epidemiology and Preventive Medicine, College of Public Health, 
National Taiwan University, Taipei, Taiwan. ${ }^{3}$ Innovation and Policy Center for Population Health and Sustainable Environment, College of Public Health National Taiwan University, Taipei, Taiwan.

Received: 11 December 2018 Accepted: 16 April 2019

Published online: 02 May 2019

\section{References}

1. Brown ML, Lipscomb J, Snyder C. The burden of illness of cancer: economic cost and quality of life. Annu Rev Public Health. 2001;22:91-113.

2. Ferlay J, Soerjomataram I, Dikshit R, Eser S, Mathers C, Rebelo M, Parkin DM, Forman D, Bray F. Cancer incidence and mortality worldwide: sources, methods and major patterns in GLOBOCAN 2012. Int J Cancer. 2015;136: E359-86.

3. Fidler MM, Bray F, Soerjomataram I. The global cancer burden and human development: a review. Scand J Public Health. 2018:46:27-36.

4. Fitzmaurice C, Dicker D, Pain A, Hamavid H, Allen C, Woodbrook R, Wolfe C, Sanabria J, Hay R, Rojas-Rueda D, et al. The global burden of cancer 2013. JAMA Oncol. 2015;1(4):505-27.

5. GBD 2015 Risk Factors Collaborators. Global, regional, and national comparative risk assessment of 79 behavioural, environmental and occupational, and metabolic risks or clusters of risks, 1990-2015: a systematic analysis for the Global Burden of Disease Study 2015. Lancet. 2016:388:1659-724.

6. Global Burden of Disease Cancer Collaboration. Global, regional, and national cancer incidence, mortality, years of life lost, years lived with disability, and disability-adjusted life-years for 32 cancer groups, 1990 to 2015. A systematic analysis for the global burden of disease study. JAMA Oncol. 2017;3(4):524-48.

7. International Agency for Research on Cancer. World cancer report 2014. World Cancer Rep. 2014;16.

8. Sim X, Ali RA, Wedren S, Goh DL-M, Tan C, Reilly M, Hall P, Chia K-S. Ethnic differences in the time trend of female breast cancer incidence: Singapore, 1968-2002. BMC Cancer. 2006;6(261):1-11.

9. Youlden DR, Cramb SM, Yip CH, Baade PD. Incidence and mortality of female breast cancer in the Asia-Pacific region. Cancer Biol Med. 2014;11: 101-15.

10. Katanoda K, Hori M, Matsuda T, Shibata A, Nishino Y, Hattori M, Soda M, loka A, Sobue T, Nishimoto H. An updated report on the trends in cancer incidence and mortality in Japan, 1958-2013. Jpn J Clin Oncol. 2015;45(4): 390-401.

11. Torre LA, Bray F, Siegel RL, Ferlay J, Lortet-Tieulent J, Jemal A. Global cancer statistics, 2012. Cancer J Clin. 2015;65(2):87-108.

12. Oh C-M, Won $Y$-J, Jung K-W, Kong H-J, Cho H, Lee J-K, Lee DH, Lee KH, Registries TCOP-BRC. Cancer statistics in Korea: incidence, mortality, survival, and prevalence in 2013. Cancer Res Treat. 2016;48(2):436-50.

13. Taiwan Cancer Registry. Taiwan Cancer Registry Annual Report. Taipei: Departmant of Health, Executive Yuan; 2017.

14. Hwang J-S, Wang J-D. Monte Carlo estimation of extrapolation of qualityadjusted survival for follow-up studies. Stat Med. 1999;18:1627-40.

15. Chen P-C, Lee J-C, Wang J-D. Estimation of life-year loss and lifetime costs for different stages of colon adenocarcinoma in Taiwan. PLoS One. 2015;10(7):1-11.

16. Chu P-C, Wang J-D, Hwang J-S, Chang Y-Y. Estimation of life expectancy and the expected years of life lost in patients with major cancers: extrapolation of survival curves under high-censored rates. Value Health. 2008:11:1102-9.

17. Fang CT, Chang YY, Hsu HM, Twu SJ, Chen KT, Lin CC, Huang LYL, Chen MY, Hwang JS, Wang JD, et al. Life expectancy of patients with newly-diagnosed HIV infection in the era of highly active antiretroviral therapy. Q J Med. 2007:10:97-105.

18. Ho JJ, Hwang J-S, Wang J-D. Life-expectancy estimations and the determinants of survival after 15 years of follow-up for 81,249 workers with permanent occupational disabilities. Scand J Work Environ Health. 2006 32(2):91-9.

19. Hsu C, Wang J-D, Hwang J-S, Tien H-F, Chang S-M, Cheng A-L, Chen Y-C, Tang J-L. Survival-weighted health profile for long-term survivors of acute myelogenous leukemia. Qual Life Res. 2003;12(5):503-17.

20. Hwang J-S, Wang J-D. Integrating health profile with survival for quality of life assessment. Qual Life Res. 2004;13(1):1-10.
21. Liu P-H, Wang J-D, Keating NL. Expected years of life lost for six potentially preventable cancers in the United States. Prev Med. 2013:53:309-13.

22. Wu T-Y, Chung C-H, Lin C-N, Hwang J-S, Wang J-D. Lifetime risks, loss of life expectancy, and health care expenditures for 19 types of cancer in Taiwan. Clin Epidemiol. 2018;10:581-91.

23. Corazziari I, Quinn M, Capocaccia R. Standard cancer patient population for age standardising survival ratios. Eur J Cancer. 2004;40(15):2307-16.

24. Rossi S, Baili P, Capocaccia R, Caldora M, Carrani E, Minicozzi P, Pierannunzio D, Santaquilani M, Trama A, Allemani C, et al. The EUROCARE-5 study on cancer survival in Europe 1999-2007: database, quality checks and statistical analysis methods. Eur J Cancer. 2015:51:2104-19.

25. Ahmad OB, Boschi-Pinto C, Lopez AD, Murray CJL, Lozano R, Inoue M. Age standardization of rates: a new WHO standard. Geneva: World Health Organization; 2001

26. Youlden DR, Cramb SM, Baade PD. The international epidemiology of lung cancer: geographical distribution and secular trends. J Thorac Oncol. 2008; 3(8):819-31.

27. Coleman MP, Quaresma M, Berrino F, Lutz J-M, Angelis RD, Capocaccia R, Baili P, Rachet B, Gatta G, Hakulinen T, et al. Cancer survival in five continents: a worldwide population-based study (CONCORD). Lancet Oncol. 2008;9(8):730-56.

28. Lee W-C, Liaw Y-P. Optimal weighting systems for direct age-adjustment of vital rates. Stat Med. 1999;18(19):2645-54.

29. Lee W-C. Standardization using the harmonically weighted ratios: internal and external comparisons. Stat Med. 2002;21:247-61.

30. Perme MP, Stare J, Est'eve J. On estimation in relative survival. Biometrics. 2012:68:113-20.

31. Lee W-C. Quantifying the future impact of disease on society: life table-based measures of potential life lost. Am J Public Health. 1997;87(9):1456-60.

32. Lee $\mathbf{W}-\mathrm{C}$. The meaning and use of the cumulative rate of potential life lost. Int J Epidemiol. 1998;27(6):1053-6.

33. Andersson TML, Dickman PW, Eloranta S, Lambert PC. Estimating and modelling cure in population-based cancer studies within the framework of flexible parametric survival models. BMC Med Res Methodol. 2011; 11(96):1-11.

34. Angelis RD, Capocaccia R, Hakulinen T, Soderman B, Verdecchia A. Mixture models for cancer survival analysis: application to population-based data with covariates. Stat Med. 1999;18(4):441-54.

35. Lambert PC, Thompson JR. Estimating and modeling the cure fraction in population-based cancer survival analysis. Biostatistics. 2007:8(3):576-94.

\section{Ready to submit your research? Choose BMC and benefit from:}

- fast, convenient online submission

- thorough peer review by experienced researchers in your field

- rapid publication on acceptance

- support for research data, including large and complex data types

- gold Open Access which fosters wider collaboration and increased citations

- maximum visibility for your research: over $100 \mathrm{M}$ website views per year

At BMC, research is always in progress.

Learn more biomedcentral.com/submissions 